This item was submitted to Loughborough's Research Repository by the author.

Items in Figshare are protected by copyright, with all rights reserved, unless otherwise indicated.

\title{
Securing and scaling resilient futures: neoliberalization, infrastructure, and topologies of power
}

PLEASE CITE THE PUBLISHED VERSION

http://dx.doi.org/10.1068/d14154p

PUBLISHER

C) SAGE Publications Ltd.

VERSION

AM (Accepted Manuscript)

\section{PUBLISHER STATEMENT}

This work is made available according to the conditions of the Creative Commons Attribution-NonCommercialNoDerivatives 4.0 International (CC BY-NC-ND 4.0) licence. Full details of this licence are available at: https://creativecommons.org/licenses/by-nc-nd/4.0/

\section{LICENCE}

CC BY-NC-ND 4.0

\section{REPOSITORY RECORD}

Sage, Dan, Pete Fussey, and Andrew Dainty. 2015. "Securing and Scaling Resilient Futures: Neoliberalization, Infrastructure, and Topologies of Power”. Loughborough University. https://hdl.handle.net/2134/18994. 
'Resilient to what, where, and for whom?' -

On the Scalar Politics of Resiliency in

the UK Critical Infrastructure Resilience Programme.

\section{Key words: Resilience, Scalar Politics, Governmentality,}

Words count: 9894

\section{Abstract}

Systemic concepts of resilience have proliferated across governance contexts, especially critical infrastructure planning and policy. These concepts promise to enhance the perpetuation of nations, governments, organizations, communities and citizens, and undergirding infrastructures, against existential threats. While the prevalence of systematic resilience thinking spans numerous policy appropriations, the scaling of resilience is remarkably consistent: resilient systems are said to encompass a hierarchy of enveloping levels and authorities - persistence and stability at larger scales accompanied by significant and fast perturbations at smaller scales. Drawing on empirical engagement with the UK's critical infrastructure policies and practices, this paper problematizes this hierarchical scalar axiom. Such treatments of scale are shown to contribute to a specific scalar politics, wherein 
the imperative for, and reification of, infrastructure resilience, is bound up with the (re)scaling of neoliberal governmentalities, rendering some subjects and objects as visible, thinkable and actionable to resilience while obscuring and eliding others. In the light of this problematization we propose an alternative, flatter scaling of infrastructure resilience, drawing inspiration from the flat ontologies of Bruno Latour, decentralized future infrastructure scenarios and the accounts of infrastructure practitioners themselves.

\section{Introduction}

Almost all evocations of resilience prefigure particular spatio-temporal scalings, from the long-term capacity of ecosystems to endure climate change to individual abilities to overcome childhood traumas. The much-cited resilience theorist, C.S. Holling, views the scaling of resilience in any system in hierarchical terms: the local levels of a system may substantially change in response to intensive, short-lived disturbances, but the resilient whole, and its function, persist over far longer time frames (Holling, 1973; 2001). Accordingly, deliberation about the politics of resilience is usually limited to addressing and prioritizing the essential functions of already given whole systems, whether technological, ecological or sociological systems, or various hybrids (Folke, 2006; Holling, 2001; Gunderson and Holling 2001; Mayena, 2006). Such political practices classify specific objects and subjects as 'critical' to the fate of a whole system, while relegating others to a hinterland of localized, short-lived perturbations which necessarily appear more marginal, even obscure.

Thus the political consequences of resilience implicitly extend beyond deliberation about 
the relative value of already given systems, and include resilience discourse itself, its scalar rationalities and politics.

In this paper we problematize the scalar politics of resilience discourse by exploring UK critical infrastructure through engagement with policy and infrastructure practitioners. Despite its relatively recent emergence within policy (Raco and Street, 2012; Mayena, 2006; Walker and Cooper, 2011), the term 'resilience' has become a central motif within UK Civil Contingencies planning, especially related to infrastructure (Coaffee et al., 2009). While policy definitions of resilience are far from universal (Coaffee et al., 2009), the Civil Contingencies Secretariat (CCS) has recently sought to standardize terms: "Resilience is the ability of assets, networks and systems to anticipate, absorb, adapt to and / or rapidly recover from a disruptive event" (Cabinet Office, 2011: 15). However resilience policy is far the exclusive preserve of government: almost all UK CNI (Critical National Infrastructure), from transport to finance, involves non-governmental organizations, many based oversees. Resilience policy thus typifies the classic (neo)liberal problem of security (cf. Foucault, 1991), where government must shape the 'conduct of conduct' of seemingly 'free' citizens and organizations, with diverse ends (Dean, 1999; Lemke, 1991; Rose, 1996).

Within UK critical infrastructure policy scale is defined axiomatically, corresponding to a nested hierarchy of enveloping levels and sizes. The hierarchical division of labour between 'gold', 'silver' and 'bronze' responders to respective strategic, tactical and operational decision-making, ushered in by the 2004 Civil Contingencies Act, is exemplary in this regard: 
The geographies of the decision are thus hierarchical and scalar even whilst the resilience literature claims that response and cooperation should not be bounded by 'hierarchical relationships' (p2887).

Such scalings may appear mandatory within a neutral division of labour, necessary and unavoidable perhaps to achieve efficient and accountable (Adey and Anderson, 2011: 2896), emergency planning and response. However, such scalings also contribute to a specific politics, wherein the imperative for resilience is wedded to the reproduction of interwoven organizations, interests, and materialities, not least infrastructure configurations.

This paper has two objectives. First, we seek to problematize the extant spatial grammar of resilience in order to gain greater purchase of the political consequences of resilience discourse (following like-minded critical readings, see: Raco and Street, 2012; Walker and Cooper, 2011). Secondly, we propose an alternative, less hierarchical, scaling of resilience. As we focus upon the first task of understanding the political scaling of resilience we circulate around a seemingly simple set of questions: 'Resilient to what, where, and for whom?' Here we follow a Foucauldian drift that considers how different (resilient) concepts, objects and subjects are rendered more or less visible, knowable and actionable, over time (Foucault, 2004a, 2004b). Analytically, this task involves recognition of the importance of genealogical stories about the origins of resilience in psychology and ecology thinking that have elided how systemic resilience discourse brings into being a particular scalar politics, 
which is highly commensurate with neoliberal governmentalities, and which can be challenged through alternative scalings of resilience.

These two objectives are pursued across three main areas of analysis. In the first part, we identify key theoretical approaches important for forging an understanding of the scaling of resilience. Here we outline the imperative for such critical analyses of the scaling of resilience, considering debates around the social construction of scale and governmentality. Following this, we conceptualize scalar politics before extending this analysis to address psychological and ecological scalings of resilience. In the second part, we examine the scaling of UK resilience policy to elaborate what we term here the art of 'governing through resilience'. This analysis is then broadened empirically to consider alternative scalings of resilience, drawing upon: the example of transport infrastructure; two influential futures studies; and interviews with UK resilience practitioners (infrastructure planners, infrastructure operators, resilience consultants, emergency planners and responders). At this juncture in the paper we question to what extent the hierarchal scalar axioms described in policy are likely to be sustained as infrastructure networks evolve, and how alternative scalar configurations of resilience might usefully develop. By way of conclusion, the third part of the paper reflects upon the contribution scalar analysis of the art of governing through resilience can offer, both to citizens subjected to its remit and scholars interested in pursuing critical analysis of resilience policy and practice.

\section{PART 1. THEORISING THE SCALING OF RESILENCE}




\subsection{The case for critical analysis of the scaling of resilience discourse}

In conducting this analysis we join an array of authors whom over the last couple of decades have considered spatialized (and to a lesser extent temporalized) scales as politicized social constructions rather than ontological givens (Smith, 1992: 73; Marston, 2000: 220; Moore, 2008: 204). Here scale "not only frames knowledge but also possesses the power to construct and change material reality" and can be "intentionally manipulated for political and economic gain" (Manson, 2008: 783). What has become termed the 'social construction of scale' (Marston, 2000) has thus been implicated within divergent political matters of concerns, from the suppression of indigenous peoples to the actions of multi-national corporations (see Howitt, 2002). Yet despite the prominent scaling of resilience, this constellation of work has not, thus far, considered resilience discourse, and by extension its reworking of neoliberal governmentalities of security.

On initial inspection, the 'worst-case scenario' and 'responsibility' rhetoric of much resilience policy (see Cabinet Office, 2010; 2011) seemingly simple confirms Foucauldian expositions of neoliberal security discourse - foregrounding tensions between the operation of (i) indeterminate, precautionary, and exceptional, (extra)juridical-disciplinary power, alongside (ii) more quotidian, subtle, governmental power that enables the individual selfpolicing of diverse risks by responsible and calculating citizens (see Amoore, 2011; Aradau and Van Munster, 2007; Mythen and Walklate, 2006; de Goede and Randalls, 2009). Yet, 
such analysis does not address how governments intervene after the aleatory event, to recover, repair, rebuild and adapt social (and technical) relations, as per resilience discourse (Cabinet Office, 2010; 2011; Coaffee et al., 2009). Instead recent analyses of security and risk (e.g. Amoore, 2011; Aradau and Van Munster, 2007; Mythen and Walklate, 2006; de Goede and Randalls, 2009), focuses upon the proactive role of government to arrange things in such a way that, through a certain number of means, such and such ends may be achieved' (Foucault, 1991: 95). Indeed this proactive orientation permeates Foucault's influential February $1^{\text {st }} 1978$ 'govermentality' lecture (Foucault, 1991), where Foucault's analysis explicitly centres upon governmental techniques of prediction, monitoring, planning and regulation that attempt to define, shape, and fulfil, in advance the diverse 'needs' and 'aspirations' of the 'population' and/or 'individual' (Foucault, 1991: 100).

In the light of the English translation of Foucault's entire Collège de France lecture series (Foucault, 2009) we can challenge this proactive orientation and admit retroactive practices under the rubric of governmentality. Foucault's (2009) analysis of eighteenth century French famine is especially beneficial to this task. Foucault (2009: 30-42) describes how the French government sought to enhance retrospective responses to famine than eliminate it entirely. Specifically the French government: increased freedom in grain trade to avoid exponential price increases, associated with juridical-disciplinary trade restrictions (e.g. price controls, trade embargos); this liberalization allowed prices to rapidly increase when harvests failed, creating pronounced scarcity (and starvation), but in turn inviting importers and domestic producers alike to flood the market to profit from increased demand and prices; thus 
quickly reducing prices and inhibiting general food scarcity and social revolt. Foucault (2009) contends the aim of security thus becomes:

finding support in the reality of the phenomenon, and instead of trying to prevent it, making other elements of reality function in relation to it; in such a way that the phenomenon is cancelled out, as it were (p59)

Foucault's (2009) analysis suggests that governmental, unlike juridical-disciplinary, power, is concerned with arranging relations to respond positively to a perturbation after the event; in other words Foucault is describing what amounts to a nascent resilience theory as the distinctive feature of (neo)liberal security and governance. Moreover, as Foucault (2009: 4445) explains the shift from centripetal (or hierarchical, centralizing, strategic planning) to centrifugal (or expansive, decentralizing, operational response) logics of governance is a particular apposite feature of governmental power. Thus in addressing the scalar politics of resilience discourse we seek to better understand practices of neoliberal governmentality, beyond proactive modalities. Before proceeding further in this task we will clarify exactly how scale, and specifically scalar politics, is being conceptualized here.

\subsection{Conceptualizing Scalar Politics}


Mackinnon (2011: 29) proposes the term 'scalar politics' can be usefully contrasted to concept 'politics of scale' (Cox, 1998; Smith, 1993), insofar as we can replace the notion that "the politics of scale are fundamentally about scale with the idea that particular political projects and initiatives have scalar aspects and repercussions" (p29). Similarly, Moore (2008: 212) surmises that within the 'politics of scale', scale often remains a fetishized causal explanas, part of our socio-spatial ontology, rather than an explanandum (that requiring explanation). Moore (2008) recommends that we should bear in mind that "the degree to which 'scale' shapes social life is an open question to be addressed empirically, rather than treated as a starting point of any research" (p218). However we reject the notion that scale is purely an epistemological frame, albeit with material consequences (Moore, 2008: 214). Yet we also do not follow Mackinnon's (2011) critical realist suggestion that any spatio-temporal scaling is capable of independence from its relations. Mackinnon's (2011) conceptualization of relations as "individual actors conceptions of them" (p30) appears to us as equally bound by representational registers. Instead we follow a Latourian trajectory towards scale and widen our notion of actors and relations to include all manner of non-human actors and possible relations, all considered constitutive of scale (Bickerstaff and Agyeman, 2009):

So here again the voluntarily blind ANT [Actor Network Theory] scholar should keep asking the same mean and silly questions whenever a well-ordered pecking order between scales has been staged: 'In which room? In which panorama? Through what medium? With which stage manager? How much?' (Latour, 2005: 190) 
Contra Marston et al.'s, (2005) use of a Deleuzo-Latourian flat ontology to reject the politics of scale; Latour (2005) himself does not encourage us to eviscerate scale from our analysis per se, but rather pay more attention to the heterogeneous sites through which scaling occurs:

I hope it's clear that this flattening does not mean that the world of the actors themselves has been flattened out. Quite the contrary, they have been given enough space to deploy their own contradictory gerunds: scaling, zooming, embedding, 'panoraming', individualizing, and so on (p220)

In a recent article Latour et al. (2012) develop these ideas around scaling further and argue - via an examination of digital profile searches and visualization techniques - that appeals to a hierarchical ontology of scale, between wholes and parts, may be the (unintended) biproduct of our inability to adequately view the relational complexity of actors. Latour explains that an actor, perhaps an author of a paper, appears atomised when you start a digital profile search (Latour, 2012: 7). Yet, as you follow it, the 'it' effectively "'fills in' with more and more elements that specify it more and more until the observer considers that he or she knows enough and begins to take the name of the entity for the entire list" (p7). Yet this entity is not a whole. Rather, in Latour's words, drawing on Leibinz via Gabriel Tarde, such an entity resembles a monad: "a point of view on all the other entities taken severally and not as a totally" (Latour et al., 2012: 7). And moreover, "Each of the attributes used in order to define the entity is itself modified by becoming the attribute of this entity" (Latour 
et al., 2012: 8). Such transformations occur because not only are entities "fully deployed through their attributes", but "each attribute is nothing but the list of actors making it up" (Latour et al., 2012: 8). Thus, for Latour et al (2012), notions of hierarchically scaled endpoints, wholes and parts, macro and micro levels, appear redundant given such continuous, dynamic, and relational, transformations, of elements and aggregates. Put simply, 'the whole is always smaller that its parts' (Latour et al., 2012).

How then might this Latourian understanding of scaling inform an analysis of scale and governmentality. Latour et al., (2012: 8-9) propose that vertical scaling, or what they call the "two-level standpoint" (Latour et al., 2012: 2), is effectively the outcome of our technical inability to view actors as Tardian-Leibnizian, relational, transformative monads. For Latour et al. (2012: 8) there may also be good ethical, and we might add financial, reasons to prevent access to such relational datasets. Such issues can be informed by the governmentality and scale literatures. As Foucault (1991: 99-101) makes clear, governments are in many was defined by their access to large (increasingly digitized) statistical datasets on populations, perhaps enabling glimpses of the relational complexities Latour et al. (2012) identifies. However, governments persist in upholding invariably scalar understandings of society. This practice appears partly, if not wholly, explainable in terms of the imperative that they reproduce individuals are tied to hierarchically arranged containers of society ('national', 'regional', 'local' etc.) to reproduce state authority (Brenner, 2004; Ferguson and Gupta, 2002; Macleod and Goodwin, 1999; Paasi, 1996). Even if the perseverance of scale is in principle explainable as a technical issue (related to access to datasets), it must also be understood alongside the political imperative for particular social aggregates, especially but 
not only national-states, to invariably deny the Latourian slogan that the 'whole is always smaller than its parts' (Latour et al., 2012). The political consequences of such axiomatic scalings are widespread, not least within the context of resilience theorising, which is where we will now turn.

\subsection{Scaling resilience}

Concepts of resilience emerged in psychology and ecology during the mid to late twentieth century (Coaffee et al., 2009; Mayena, 2006. For psychologists, the spatio-temporal scale of resilience is not the human mind as might be assumed, but rather a population of individuals, observed over a given time whom typify particular characteristics (behaviours and lifestyles) that can be statistically mapped onto a "general pattern" who adapt positively to threat or adversity (Masten and Powell, 2003: 4). The task of psychology then becomes to explain such aggregated patterns (Luthar et al. 2000: 544): "It is also important to keep in mind that identifying resilience from implicit or explicit diagnostic criteria is not assumed to describe people in totality or to define their lives at all time" (Masten and Powell, 2003: 4). In sum, psychologists adopt a hierarchical upscaling of resilience, wherein an aggregate's diagnosable resilience as a total population exceeds any particular individuals (e.g. Bonanno, 2004; Luthar et al. 2000; Masten, 2001).

The ecologist, and well-cited resilience theorist, Holling (1973) repeats this upscaling of resilience: "Resilience determines the persistence of relationships within a system and is a 
measure of the ability of these systems to absorb changes of state variables, driving variables, and parameters, and still persist" (p17). In other words, resilience is understood as a capacity for variables, or parts of a system to change structure and function, while the whole, and its function, 'persists' (Holling, 2001; Gunderson and Holling 2001). And thus: “A management approach based on resilience..would emphasize the need to keep options open, the need to view events in a regional rather than a local context and the need to be emphasize heterogeneity" (Holling, 1973: 21; see also Folke, 2006). Folke (2006) explains how within Holling's systemic model, "Each level operates at its own pace, embedded in slower, larger levels but invigorated by faster, smaller cycles" (p259). This view implies the larger the scale we describe, the slower, more stable, and indeed perhaps more resilient, the system appears.

As concepts of resilience were translated into the social sciences, this hierarchical upscaling of resilience is retained: "macro-level social structures are seen as providing structural conditions within which micro-level processes unfold, which in turn transform macro-level structures through feedback mechanisms that favour the generation or confirmation of rule systems" (Davidson, 2010: 1144; see also Folke, 2006). Holling (2001) explains similarly how macro-scales tend to imbue social stabilisation: "cultures of different people establish norms that guide the actions of human individuals" (p397). Despite stressing the possibility of adaptation occurring throughout all scales (Holling, 2001: 394), across Holling's work, the 'local' appears the site of innovation to engender rapid (mal)adaptations (Holling, 1973; 2001; Gunderson and Holling 2001) contrasted with slower, more stable and obdurate macro-scales. Despite some criticism of the characterization of the global as static and local as variable (Davidson, 2010), this hierarchical, or in Holling's parlance 'panararchical' 
(Holling 2001; Gunderson and Holling 2001), upscaling of resilience appears to have percolated into emergency planning contexts. A particularly important element of this trend is the notion of functional resilience. Inspired by, though to some extent departing from (see Folke, 2006: 256), the socio-ecological systems approach of Holling: disaster management theorists have conceptualized resilience as the capacity of a whole system to continue an essential (and pre-defined) function despite experiencing profound, though perhaps shortlived, changes to its component structure (e.g. Mayena, 2006; Rose, 2007).

\section{PART 2: GOVERNING THROUGH RESILIENCE}

\subsection{The Case of the UK Critical Infrastructure Resilience Programme}

It is beyond the scope of this study of provide a comprehensive review of resilience scaling within UK policy contexts (see e.g. Coaffee et al., 2009). Instead, this analysis will focus in detail on two recent policy documents related to UKCIR (UK Critical Infrastructure Resilience): (i) Strategic Framework and Policy Statement (SFPS) on Improving the Resilience of Critical Infrastructure to Disruption from Natural Hazards (Cabinet Office, 2010) and (ii) Keeping the Country Running (KCR): Natural Hazards and Infrastructure For Consultation: A Guide to improving the resilience of critical infrastructure and essential services (Cabinet Office, 2011). These documents are intended to serve as a touchstone for the development of resilience standards across a diverse range of practitioners and contexts. Both of these documents were developed through extensive cross-sector consultation as part of the 
Critical Infrastructure Resilience Programme (UKCIRP) initiated by the Civil Contingencies Secretariat of the Cabinet Office in 2009 in response to Sir Michael Pitt's criticisms of the response to the summer floods of 2007 :

The approach taken by the Government to mitigating the risks to critical infrastructure from flooding and other natural hazards has been uncoordinated and reactive. There is no central understanding of the level of risk to which critical infrastructure, and hence wider society is exposed; and there is no centrally defined standard against which to drive action. (Pitt, 2007: ES.88/xxvii)

Notably, Pitt explicitly refers to the need for government to centralize knowledge and action to protect wider society: national governance is criticized, yet remains the default frame of reference to understand critical infrastructure resilience.

The SFPS sets out the "proposed policy intent, scope, aims, timescales and work streams" (Cabinet Office, 2010: 4) to improve UKCIR in relation to Pitt's specific recommendations. The SFPS provided an interim standard for UKCIR, to inform annual National Infrastructure Plans (NIPs) setting out government infrastructure policies and investments. A key aspect of the SFPS is a specific spatial hierarchy of UKCIR:

The UK's national infrastructure is defined by the Government as: "those facilities, systems, sites and networks necessary for the functioning of the country and the delivery of the essential services upon which daily life in the UK depends". (Cabinet Office, 2010: 8). 
However, the SFPS also includes this caveat:

From the perspective of the consumer, what matters is the loss of an essential service, irrespective of whether it arises from the loss of either national or local infrastructure assets (Cabinet Office, 2010: 8).

Thus, critical national infrastructure (CNI) is identified alongside critical local infrastructure (CNL). The rationale for this distinction is then explained:

This will enable assets, systems or networks not otherwise deemed as critical national infrastructure to be evaluated and included within the Programme if doing so would be appropriate and proportionate. However, the risk-based approach that underpins the Programme means that initial vulnerability analysis will focus on the Critical National Infrastructure (Cabinet Office, 2010: 8).

This passage offers three important insights. First, it clearly suggests the SFPS invites us to conceptualize resilience through hierarchically nested levels. Secondly, resilience of the 'nation' as a whole is rendered visible and actionable, while 'local' resilience appears only visible and actionable if it can be shown to relate to the immediate, and calculable, risks facing the 'nation'. Notably, the SFPS utilizes the classified National Risk Assessment (NRR) to calculate national risks on a 5 year horizon to determine the risk-level of threats to critical infrastructure. Thirdly, the SFPS does suggest that while we might usefully consider sites not previously considered along the conflated CNI/UKCIR list, we should focus our analysis on 
$\mathrm{CNI}$ as we can already calculate these sites as important, because they are already identified in the NRA.

The emphasis in the SFPS on already known 'national' risks through the conflation of CNI/UKCIR is somewhat surprising. The Pitt review (Pitt, 2007: xi), for example, makes clear the need to foreground the unpredictability and openness of future threats, as well as the lack of current knowledge about emergent sites of UKCIR (Pitt, 2007: xxx). The consultation documents for the SFPS suggest further equivocality surrounding the scaling of resilience:

The Government has defined "critical national infrastructure". The Pitt Review talked more generally of "critical infrastructure and essential services". How do you define what is "critical" for the infrastructure in your organisation / sector? (SFPS consultation, 2010: 14).

While consultation responses overlooked the scaling of resilience - instead interpreting the question as 'what is critical to your organisation' (SFPS consultation, 2010: 14) - this question indicates some openness to discuss the scaling of resilience. However, the upscaled conflation of UKCIR and CNI pervades the SFPS, including in the definition of the nine constituent sectors of $\mathrm{CNI}$ (health, communications, emergency services, water, energy, transport, food, governance and finance) (Cabinet Office, 2010: 24), and the 5 levels of criticality of CNI (Cabinet Office, 2010: 25); no subsequent mention is made of 'critical local infrastructure' beyond the opening caveat. 
The KCR document was published by the UKCIRP in 2011 in the wake of consultation about the SFPS (and after the May 2010 change from a Labour majority government to a Conservative-led coalition). The stated purpose of the KCR is to provide a set of standards, to infrastructure operators, emergency responders, regulators, third-sector organisations and government, to improve UKCIR. The KCR invited further consultation on UKCIR standards, feeding into the 2011 NIP. The KCR was also framed as a response to the 2010 National Security Strategy - A Strong Britain in an Age of Uncertainty (NSS, 2010) - which highlighted infrastructure resilience as a national security concern (Cabinet Office, 2011: 7). The KCR focuses upon natural hazards, following the areas of concern identified in the SFPS and the Pitt report. Compared to SFPS, the KCR noticeably dilutes government responsibility for UKCIR (compare Cabinet Office, 2011: 11 with Cabinet Office, 2010: 10); in keeping with the professed reduction of 'big' government by the Conservative-led coalition.

The KCR follows the SFPS in developing a nested hierarchical approach to resilience, which prioritizes the 'national', while also not entirely overlooking the 'local':

Critical infrastructure is therefore a broad term used to describe CNI and other infrastructure of national significance as well as infrastructure and assets of local significance (Cabinet Office, 2011: 13).

The KCR acknowledges that:

For the purposes of civil emergency planning, the emergency responders may decide to make special provisions for other infrastructure of primarily local significance 
(critical local infrastructure or assets) in their emergency response plans. These might include arrangements for infrastructure whose loss would impact on delivery of essential services, have other significant impacts within the local area, or be needed to support an emergency response (Cabinet Office, 2011: 12).

The conflation of CNI/UKCIR evident throughout the SFPS, is less apparent in the KCR. Instead the guide proposes that Local Resilience Forums (LRF) composed of local infrastructure operators, government and responders are actively involved in understanding their UKCIR, including critical local infrastructure:

owners of infrastructure should provide information on any critical infrastructure that provides essential services within the LRF area, whether the infrastructure is located within or outside of the LRF area. This should include sites where a response or support may be needed from emergency responders to manage the consequences of civil emergencies, and any critical local assets or infrastructure as determined by infrastructure owners in discussion with other local responders (Cabinet Office, 2011: 75).

A less explicit upscaling of resilience in the KCR relates to a discussion of redundancy:

The Redundancy element is concerned with the design and capacity of the network or system. The availability of backup installations or spare capacity will enable operations to be switched or diverted to alternative parts of the network in the event of disruptions to ensure continuity of services. In some of the sectors of 
national infrastructure, redundancy strategies would lead to an initial loss of performance until the alternative infrastructure can be brought into operation.. The resilience of networks reduces when running at or near capacity, although in some sectors or organisations it is recognised that it may not always be feasible to operate with significant spare capacity within the network (Cabinet Office, 2011: 16).

The debt to systems thinking (Holling, 1973; Gunderson and Holling 2001) here is not acknowledged, but the influence is striking: if the stable system (whether transport or telecommunications) is more than the sum of its dynamic parts, it follows that is also more resilient than its parts, as its unstable parts are substitutable, but its whole essential function seemingly is not.

\subsection{Towards a flatter scaling of resilience}

The upscaling of resilience evident in these policies (and others - see Adey and Anderson, 2011: 2883-2889) suggests that some infrastructure sites, and concomitant populations, are more or less substitutable parts of the socio-technical system of UK resilience. In other words, systemic concepts of resilience invariably naturalize the idea that hierarchical (up)scalings of resilience pre-exist resilience thinking. While we might rightly ask that critical discussion should interrogate what is and what is not 'national'/ 'local', 'critical' / 'noncritical' and so on, a perhaps more profoundly radical alternative is also possible: what might a flatter scaling of resilience accomplish and how might one be possible? 
The 2011 National Infrastructure Plan (HM Treasury, 2011), informed by both the resilience theorizing of the SFPS and KCR, is suggestive of the problem of systemic resilience scaling and a possible alternative. Amongst various resilience initiatives, a policy is proposed for greater operational freedoms at London's Heathrow airport:

These measures include the use of both runways for arrivals or departures in limited and prescribed UK circumstances. These could deliver real benefits in terms of resilience and in reducing late departures (particularly unscheduled night flights), stacking and carbon emissions (HM Treasury, 2011: 52).

Identifying and making use of redundancies in a 'part' of system may indeed (temporarily) increase the resilience of the whole system; in this example, increasing capacity of Heathrow would provide more flexibility in UK air travel during emergencies. However, as 'Jevons paradox' predicts, efficiency improvements, gained through the use of such redundancies, quickly become likely single points of failure, as a system even more quickly reaches full capacity as the desirability of air travel increases. Instead we might follow Latour et al. (2012) and consider what happen if we admit the parts of this 'system', individuals, communities and runways, are 'more than the [resilient] whole', in this case air transport. Indeed, 'parts' appear capable of responding to not only short-lived, localized, events, but rather altering the long-term ends of 'whole' systems. For example, when people suddenly cannot fly, as dramatically occurred across Europe during the 2010 eruption of the Icelandic volcano Eyjafjallajökull, many quickly adapted their plans, taking trains, utilizing road sharing apps for smartphones (IET, 2012), and increasing their use of teleconferencing (PR Web, 2010). Such adaptations engender substantial transformation of 
the function, not simply the component structure, of the entire transport system. As a transport behaviour expert, interviewed for this project, puts it:

It's been long recognised in transport studies that the assumption of building more infrastructure to accommodate demand can become self-defeating because it encourages more demand just as cheaper energy encourages more consumption [as in Jevon's Paradox]. And so the hypothesis was explored well does the reverse apply if you reduce capacity, do you reduce demand and a review across a number of localised episodes of bridge collapses, terrorist attacks and so on where the transport infrastructure has been compromised, has shown that traffic has disappeared; it hasn't re-routed necessarily, it's not that it's somewhere else, it's literally disappeared because when individuals are faced with destinations being less accessible they are less inclined to take the option of trying to reach that destination, and so they diversify their business to suit that.

Individuals, communities and infrastructure assets can, and do, adapt, often more than authorities, focussed upon the recovery to status quo of upscaled infrastructure systems, are willing to admit (for more examples see Cairns et al., 1998; Street and Raco, 2012). This is because actors, and their potentials to affect and be affected, are, as Latour et al. (2012) describe, never fully explainable in terms of their formal role within upscaled wholes, but rather only (partially) graspable through their transformative relations.

Accordingly, the institutionalization of systemic thinking, where resilience is scaled across enveloping hierarchies (with single points of failure, cascade effects, interdependencies, 
redundancies etc.) may actually be inadvertently contributing to future threats. This is because this mode of thinking locks government priorities and policies into a rather static model of resilience where the recovery to status quo of a priori systems and functions come to dominate the policy agenda (e.g. espoused $\mathrm{CNI}$ sites, relations and functions), and so as yet unknown sites, relations and indeed functions are already dismissed as merely 'localoperational', 'regional-tactical', 'community-household' concerns. This spatio-temporal scaling risks delimiting resilience policy around known threats and solutions, rather than encouraging reflexive, open-ended adaptation, transformation and evolution (Raco and Street, 2012).

\subsection{Re-scaling resilience (i): evolving infrastructures}

Set against a policy backdrop of prevailing resilience (up)scalings, this section will consider how the resilience of future infrastructure might become far less hierarchically scaled than past infrastructures, as influenced by moves towards decentralized physical configurations and governance arrangements. Uncertainty around the centralization of infrastructure, particularly energy and transport, is well rehearsed in future studies of infrastructure, commonly framed around tensions between globalism and localism associated with responses to energy security and climate change. Two notable examples include the Intergovernmental Panel on Climate Change's emissions scenarios (IPCC, 2000) and the energy scenarios developed by UK's Foresight Directorate in their 2008 report, Powering Our Lives: Sustainable Energy Management and the Built Environment (SEMBY) (Foresight, 2008). Both the IPCC and SEMBY scenarios are sharply contrasted on the basis of scale: A1 
and B1 IPCC scenarios families (IPCC, 2000: 179-180; 181-182), and SEMBY's Carbon Creativity and Green Growth scenarios (Foresight, 2008: 71-73) describe a globally convergent and interdependent world, whereas A2 and B2 scenario families (IPCC, 200: 180181; 182-183), and SEMBY's Resourceful Regions and Sunshine State (Foresight, 2008: 68-70) scenarios, describe a higher level of local divergence and independence. The IPCC scenarios are thus differentiated:

Simplifying the complex dynamic patterns of technological change across the scenario groups, one conclusion is that perhaps the single most important dichotomy of energy technologies of relevance for future GHG emissions is between advancements in "clean coal" and other fossil (e.g. methane hydrate) technologies (delivering electricity, gas, or synliquids) and those of decentralized hydrogenpowered fuel cells, combined with nuclear and renewable energy (for hydrogen production). The first, GHG-intensive technology cluster largely follows traditional centralized technological configurations of the energy sector. The latter represents both radical organizational and technological changes. The revolutionary change may well be less the hydrogen-powered fuel cell car itself, but rather that it could generate electricity when parked, dispensing entirely the need for centralized power plants and utilities. (IPCC, 2000: 217).

The SEMBY scenarios (Foresight, 2008) are similarly differentiated: 
The scale of future energy systems in the UK will have a significant impact on the evolution of the built environment. Yet as we have seen the scale at which energy systems emerge is closely connected with social and economic values and behaviours and the nature of governance at local and national levels. Today's centralized energy system has a particular relationship with the built environment through the way people understand and use energy services. Electricity is centrally generated in remote power plants; the majority of heating services are fuelled by gas which is centrally distributed; and petrol for vehicles is refined and distributed through a few large depots. A key issue for decision makers is whether the strongly centralised approach to energy provision that developed in the post-war period can continue to meet the needs of the economy and society over coming decades (Foresight, 2008: 106).

Current UK infrastructure, especially energy, remain highly centralized: resilience is thus increased through identifying, protecting and repairing single points of failure - critical national infrastructure - that could cause cascade effects across the country (see Cabinet Office, 2010; 2011; HM Treasury, 2011). Even famously 'decentralized infrastructures' such as the internet, actually exhibit a remarkable amount of centralization, particularly within nation-states, around key data hubs and undersea data cables, as well as through their intersection with more heavily centralized infrastructures, including the energy grid (see Blum 2012). Moreover, despite the existence of alternative future scenarios, in emergency planning contexts, infrastructure is routinely 'black-boxed'. For example, Adey and Anderson's (2011) ethnographic analysis of UK emergency planning and response exercises suggests that while emergency response as a critical infrastructure is itself regularly 
problematized, its changing relationship to other critical infrastructures is not. Instead, the infrastructure contexts within which emergency planning and response exercises take place are more or less a projection of current infrastructure, not least to ensure plausibility (see Adey and Anderson, 2011: 1103-1104).

\subsection{Re-scaling resilience (ii): engaging practitioners}

In this section we will consider interviews with a sample of UKCIR practitioners and organizations $(n=27)$, some of whom were involved in the development of the SFPS and KCR, to understand how resilience may alter in the light of such decentralized future infrastructure scenarios, and the extent to which the hierarchally scaled visions of resilience are beneficial in practice. The rationale for focussing upon future UKCIR here is twofold: first, practitioners can more openly discuss basic resilience assumptions unencumbered by corporate and governmental confidentiality and secondly, it is likely that future scalings of infrastructure, and by extension their resiliencies, may be radically different to the present, prompting a more open discussion of resilience scalings, and their implications (something which current emergency planning exercises do not: see Adey and Anderson, 2011, 2012). Yet, while practitioners were encouraged to discuss future UKCIR, they were all too aware of path-dependencies from ageing infrastructure. Transport and energy infrastructure technology was especially viewed as highly recalcitrant to change, and thus likely to significant constrain future infrastructure development: 
You can make the trains go a bit faster, you can make them carry more people inside, more comfortably. You're fundamentally stuck with two metal rails and a box on wheels (rail security planner).

You would never be able to put that infrastructure in to replace the majority of the transmission system so that everything is localised and driven by micro-generation quickly enough I think to hit our 2030 target and then out to 2050 (energy networks manager).

Much of the [railway] network was built in the 1840s so we are talking about $160 / 170$ year old earth works that nobody knows what they were built of, apart from the fact the material has been dug up from the ground fairly locally, and it's not been compacted in the way a modern earth work would be compacted when it's built (rail infrastructure manager).

It might be reasonably expected that acknowledging recalcitrance to change in turn 'locked' the UK into heavily centralized infrastructure configurations and attendant hierarchically scaled configuration of resilience as expressed in the SFPS and KCR. However, for many practitioners, this appeared far from the case: they readily identified elasticity in current infrastructure sites to traverse what appear to be locally decentralized and nationally centralized functions and relations, and by extension rescale resiliencies: 
I still think that the concept of moving large numbers of people reliably between transport hubs, there's a certain attraction to that, however the world develops, whether you go large and your hubs just get bigger, or you contract, your hubs just get smaller. You've still got the fixed link and the fixed link is fundamentally two bits of metal stretching across countryside (rail security planner).

from our point view because we are deemed to be a national asset of national importance the view from the government to us is you won't ever really be put in a place where you could be at risk of not having electricity. So the choice about whether you go off grid and do your own micro-generation or not is purely up to you based on a commercial business case [or] ethical moral case you want to make around being sustainable and everything else (airport security manager).

Practitioners also explained how understanding, and enhancing, UKCIR, did not benefit from the vision of centralized infrastructure, with single points of failure and cascade effects and so on, as explicated within the UKCIRP:

if you're looking at the rail network becoming more insular, rather than, less of a network, more of a sort of interconnected group of small networks, then I would imagine that you would see significant resilience as a national piece of infrastructure (rail security planner). 
Decentralized infrastructure networks were said to foster greater national resilience by encouraging repair cultures (Graham and Thrift, 2007):

a lot of the stuff the transition movement are doing, mending things locally like in transport with bikes, using local skills and, you know, not relying on branded equipment made on the other side of the world that you can't touch and things like that is really good for the resilience of the country as a whole (Local authority resilience planner).

Decentralization was also viewed as reducing cascade effects (and the threat of malicious attacks based on such effects):

If we move away from that [centralized] model and though the infrastructure may look like that but its functionality is reduce because the throughput is less because there are more sources locally, then you're more resilient to single point failures. I think the other also about flooding, for example, and I think it applies to terrorism is the centralisation of resources and how you only need to create damage and lack of use of single key resource like a grid supply point substation and you affect a large number of customers (Energy infrastructure manager).

And finally decentralization can co-scale the disruption to supply with the supply for demand: 
If it's done on a local basis with, say, flooding, if the flooding is local you might wipe out the local infrastructure but there's a fair change you've actually wiped out the local need for it as well... so that gives us the time to make repairs to the infrastructure while people repair the housing stock. I could see all of this would really help national resilience (Energy infrastructure manager)

All of these examples suggest that what might be currently viewed as 'local' infrastructure may be 'critical' to future 'national' resilience. Indeed, the 'nation' may actually be more not less resilient if government policy did not a priori assume that a hierarchically upscaled model of critical national infrastructure, which prioritizes the protection, repair and adaptation, of pre-known CNI, was the modus operandi of addressing perceived existential threats such as energy security and climate change.

\section{PART 3: CRITICAL REFLECTIONS ON THE SCALING OF RESILIENCE}

When discussing future infrastructure scenarios, UKCIR practitioners appear far less bound by a hierarchical (and by extension systems-orientated, functionalist-instrumentalist) scaling of resilience than extant government policies such as the SFPS and KCR suggest. These practitioners do not necessarily accept the prioritization of national over local resilience; rather national and local resilience (and by extension strategic and operational decisions) appear far more imbricated and indeed difficult to define in advance. This is perhaps not 
surprising - as Adey and Anderson (2012) suggest any apparatus of security is "always in the midst of being made and unmade, rather than indicative of a broader logic or rationality" (p100). Moreover, clearly, or perhaps hopefully, we should also remind ourselves as researchers that we are not merely passive onlookers in this process of making and unmaking security; by sharing and reviewing the above alternative infrastructure scenarios with practitioners we hope to problematize the axiomatic scalar ontologies which animate UK critical infrastructure resiliencies, and in the process open more conceptual space for alternative ways of understanding and promoting security futures.

The findings presented here also suggest that more centralized network topologies are vital in the reproduction of hierarchical scalar ontologies (and attendant neoliberal governmentalities). In their analysis, Latour et al. (2012) offer important clues as to why this might be the case; specifically, they suggest that scale is a product of incomplete knowledge of a network - evenly distributed network knowledge demands a concomitant decentralization of data access. A highly centralized network, such as the UK's energy distribution grid, is predicated on the denial of access to network data; it is (rather understandably perhaps) assumed that information about energy flows should be limited to a few actors in undisclosed command centres, or 'centres of calculation' (Latour, 1987), that can be trusted to act in good faith for the 'nation', over the interests of lower, smaller scales. Thus, hierarchical scalings of resilience, and elsewhere, are maintained as much as a technological effect of highly centralizing infrastructure configurations, as through ideological symbolism (as in Agnew, 1997; Paasi, 1996; Swyngedouw, 2007) or ontological preference (Marston et al. 2005). 
Accordingly if energy, and transport, infrastructure was to be extensively de-centralized, as described in the Foresight and IPCC scenarios above, and as encouraged by some of the practitioners above, then the scaling of UK resilience would appear decidedly flatter, if not flat. While it would, of course, be erroneous to ascribe to these practitioners the sort of flat scalar ontology proposed by Latour et al (2012), not least because they all work within a discursive field of knowledge replete with hierarchical scales (e.g. regional energy distribution companies, local authorities etc.), we can discern in their reflections about future resilience, pseudo-Latourian challenges to the possibility of always understanding resilience across pre-conceived hierarchically ordered scalar configurations. What is more, even in the past, the incongruities associated with resilience policy based on hierarchally scaled configurations have become all too evident. During interview, a local resilience officer, for example, recalled a story where she had assisted a 'critical' piece of national rail infrastructure (a train operating company and international rail station). The company had been forced to suspend its service during extreme weather, stranded passengers and staff therefore required accommodation to restart operations when the weather improved; the local resilience planner then assisted the company in finding accommodation. Such examples suggest that seemingly local (perhaps 'non-critical', 'non-essential') infrastructure - housing and hotels - can quickly become critical national infrastructure during exceptional UK circumstances, and moreover that the ends of resilience, the strategic 'function' of a system (in this case transport and accommodation), can never be entirely known in advance, but become visible during extreme episodes. 
Governmental upscaled logics of infrastructure resilience appear at best specious and at worst malicious. We are reminded here of a comment made by one resilience practitioner when discussing the 2007 summer floods: "we dealt with the 2007 floods fine and anyway even if we hadn't and the floods had taken out the power supply in Gloucester, it is only Gloucester, the country would be fine". Underpinning this statement is the hierarchically scaled, systemic view of resilience, derived from ecological and psychological notions of systems resilience, wherein the resilience of the whole appears more than its parts (Folke, 2006; Holling, 1973; 2001; Gunderson and Holling 2001). Leaving aside the systemic concern with whether Gloucester's hypothetical power outage would have caused cascade effects in national UKCIR elsewhere or not, this upscaling of resilience has the effect of potentially downgrading the immediate safety of thousands of human beings to 'component parts' subsumed under the strategic function of the national infrastructure system. While we do not wish to contest Adey and Anderson's (2011) position that the (neoliberal)state is not "self-evidently abandoning the population" (p2888); clearly a population's resilience is far from uniformly distributed, both spatially and socially (the aftermath of Katrina offers a potent case, see Price, 2008); rather, resilience modulates, amongst other things, around the development of increasingly complex, and highly centralized critical infrastructure systems, and associated policy agendas, whose variegated implications for diverse populations can only ever be partially understood in advance.

Such seeming acceptance of destruction and death has resonances with Foucault's analysis of the (limited) tolerance of famine as a means to prevent social revolt in eighteenth century France (Foucault, 2009: 30-42). In both Foucault's case and ours it seems as though 
the ultimate concern of government is not with the effect of an aleatory event on the population per se, but rather its capacity to threaten the political and economic status quo (cf. Raco and Street, 2012; Walker and Cooper, 2011). We will tentatively push this point further: a latent objective of UKCIR policy is to avoid questioning centralized infrastructure configurations and their upscaled neoliberal security configurations wherein state actors can covertly identify particular sites ('local', 'community' neighbourhood') paradoxically within, beneath and beyond their concern. The art of 'governing through resilience' could thus be defined as the problem of government concerned with assembling infrastructure together so that sites and populations can appear/disappear from being: (i) the responsibility of the state, and at the same time as (ii) essential or non-essential parts of the functioning of the nation.

Accordingly, our analysis suggests a (partial) reversal of the precautionary and self-policing logics associated with 'governing through risk' (e.g. Amoore, 2011; Aradau and Van Munster, 2007; Mythen and Walklate, 2006; de Goede and Randalls, 2009). Instead of governments indiscriminately, and proactively, acting as juridical-disciplinary powers in exceptional circumstances for the good of the majority of the population, while circulating governmental power through which citizens self-police their everyday life, the nascent (scalar) politics of 'governing through resilience' implies that governments are also more or less explicitly, and materially, pre-delimiting the limits of their power to see or not see, to act or not act, in exceptional circumstances around selective interests. Yet governments are also able to concurrently confess, most demonstrably through the rhetoric of community resilience (and Local Resilience Forums and so on), an ethos of care for the welfare of all 
citizens (Cabinet Office, 2010; 2011). There is a related corollary here for theorizing governmentalities: neo-liberalism is usually associated with de-centralized, or devolved, forms of governance (e.g. Micthell, 2001; Jenson, 2009; Peck, 2011; Perreault, 2005), not least by Foucault (2009) himself. Yet, in the light of this study, centralized, centripetal, infrastructure can appear equally, if not more, commensurate with the auspices of neoliberal governmentalities (and thus even perhaps an under-theorized aspect of the spatial selectivity of neoliberal governance - see Jones, 1997). Thus we contend, if 'critical' infrastructures (power, water, finance, health and so on) were more co-extensive around networks of households, or communities, as might be seemingly be expected to be promoted under neoliberal decentralized forms of governance, then the political, rather than technical, aspects of resilience policy would surely be rendered more visible, thinkable and actionable to more people. Thus, questions of 'resilient to what, where, and for whom?' could perhaps be variously answered.

An important caveat is required here: insofar as we promote this alternative policy direction, we are not simply advocating local over national resilience; indeed, reversing scalar hierarchies is hardly adequate to the flatter scalar analysis advocated by Latour (or indeed the scale politics literature: see Marston et al. 2005; Moore, 2008; Pain and Smith, 2008). Indeed the participatory mantra of community resilience, as laid out within national directives for the creation of Local Resilience Forums and Community Risk Agendas (Cabinet Office, 2011), is of course intimately connected to neoliberal upscaling: "social or community resilience is seen very much as the participation of citizens in the process of making the state more resilient" (Coaffee et al., p117). And paradoxically, despite the 
rhetoric of community empowerment (Cabinet Office 2010, 2011), local resilience planners are frequently inhibited by the same said highly centralized infrastructure networks which buttress their hierarchically (up)scaled modalities of resilience: we recollect an account from a local resilience planner who was repeatedly unable to gain access to regional level information from a large water company to develop a Community Risk Agenda. Thus, we seek here to problematize the political and material practices required for such (up)scalings to be effected in the first place, namely, centralized networks of infrastructure and neoliberal modes of govermentality. The potential for such radical technological change, while beyond the scope of this paper, which concerns itself instead with policy axioms, does not appear insurmountable (see e.g. Nye et al., 2010; Wolfe, 2008).

Instead of following Latour et al. (2012) and following an expansive dataset to understand critical infrastructure resilience in relationally constituted monadic terms, we have more modestly suggested the challenges and opportunities associated with such a task. It is perhaps unsurprising that governments appear predetermined to deny, or moderate, such flatter scaled alternative futures, given their wide-ranging commitment to upscaling as a technique of governmenality (Brenner, 2004; Ferguson and Gupta, 2002; Macleod and Goodwin, 1999; Paasi, 1996). However, we should still ask how much longer the (up)scaling of resilience will persist when it risks obfuscating, and inhibiting, perhaps one of the most overriding, long established, and progressive, concerns of those who govern: "the common welfare and salvation of all"' (Foucault, 1991: 94; emphasis added). 


\section{References}

Adey P Anderson B, 2011, "Event and anticipation: UK Civil Contingencies and the space times of decision" Environment and Planning A 43 2878-2899

Adey P Anderson B, 2012, "Anticipating emergencies: Technologies of preparedness and the matter of security" Security Dialogue 43 99-117

Agnew J, 1997, "The Dramaturgy of horizons: geographical scale in the 'Reconstruction of Italy' by the new Italian political parties, 1992-95" Political Geography 16 273-306

Amoore L, 2011, “Data Derivatives: On the Emergence of a Security Risk Calculus for Our Times" Theory, Culture and Society 28 24-43

Aradau C Van Munster R, 2007, “Governing Terrorism Through Risk: Taking Precautions, (un)Knowing the Future" European Journal of International Relations 13 89-115

Bickerstaff K and Agyeman K, 2009, “Assembling Justice Spaces: The Scalar Politics of Environmental Justice in North-east England" Antipode 41 781-806 
Blum C, 2012, "Mapping the internet" Fortune July $23^{\text {rd }}$

Bonanno G, 2004, "Loss, Trauma, and Human Resilience Have We Underestimated the Human Capacity to Thrive After Extremely Aversive Events?" American Psychologist 59 2028

Brenner N, 2004, New State Spaces: Urban Governance and the Rescaling of Statehood (Oxford: Oxford University Press)

Cabinet Office, 2010 "Strategic Framework and Policy Statement", Cabinet Office, London, https://update.cabinetoffice.gov.uk/resource-library/strategic-framework-and-policystatement-improving-resilience-critical-infrastructu

Cabinet Office, 2011, "Keeping the Country Running: Natural Hazards and Infrastructure", Cabinet Office, London, http://www.cabinetoffice.gov.uk/sites/default/files/resources/natural-hazardsinfrastructure.pdf

Cairns S Hass-Klau C Goodwin P B, 1998, Traffic Impact of Highway Capacity Reductions; Assessment of the Evidence (Landor Publishing: London) 
Coaffee, J Murkami-Wood, D Rogers P (2008) The Everyday Resilience of the City: How Cities Respond to Terrorism and Disaster (Palgrave: Basingstoke)

Cox K, 1998, "Spaces of dependence, spaces of engagement and the politics of scale, or: looking for local politics" Political Geography 17 1-23

Dean M, 1999, Governmentality, Power and Rule in Modern Society (Sage: London)

de Goede M Randalls S, 2009, “Precaution, pre-emption: arts and technologies of the actionable future" Environment and Planning D: Society and Space $\mathbf{2 7}$ 859-878

Ferguson J Gupta A, 2002, "Spatializing states: towards an ethnography of neoliberal governmentality" American Ethnologist 29 981-1002

Folke C, 2006, "Resilience: The emergence of a perspective for social-ecological systems analyses" Global Environmental Change 16 253-267

Foresight, 2008, Power our lives: sustainable energy management and the built environment: final project report (Government office for science: London). 
Foucault M, 1991, "Governmentality" in The Foucault Effect Eds G Burchill C Gordon P Miller (Harvester Wheatsheaf: London) pp 87-104

Foucault M, 2004a, The Archaeology of Knowledge (Routledge: London)

Foucault M, 2004b, Madness and Civilization (Routledge: London)

Foucault M, 2009, Security, Territory and Population: Lectures at the Collège de France 19771978 (Palgrave Macmillan: Basingstoke)

Graham S Thrift N, 2007, "Out of Order: Understanding Repair and Maintenance" Theory Culture and Society 24 1-25

HM Treasury, 2011, “National infrastructure plan”, HM Treasury, London, $29^{\text {th }}$ November http://www.hm-treasury.gov.uk/national_infrastructure_plan2011.htm

Holling C S, 1973, "Resilience and stability of ecological systems" Annual Review of Ecology and Systematics 4 1-23 
Holling C S, 2001, "Understanding the Complexity of Economic, Ecological, and Social Systems" Ecosystems 4 390-405

Gunderson L Holling CS Eds, 2001, Panarchy: understanding transformations in human and natural Systems (Island Press: Washington)

Howitt, 2002 "Scale", in A Companion to Political Geography Eds J Agnew K Mitchell G Toal (Wiley-Blackwell: London) pp 138-157

IET, 2012, "Innovative responses to the closing of European airspace" Ideas in Transit, http://www.ideasintransit.org/wiki/Innovative_response_to_the_closing_of_European_airs pace\#Eurostar

IPCC, 2000, "Summary for policymakers: emissions scenarios", United Nations, New York, http://www.ipcc.ch/ipccreports/sres/emission/index.php?idp=0

Jenson J, 2009, "Lost in Translation: The Social Investment Perspective and Gender Equality" Social Politics 16 446-483

Jones M R, 1997, "Spatial selectivity of the state? The regulationist enigma and struggle over economic governance" Environment and Planning A 29 831-864 
Latour B, 2005, "Reassembling the Social: An Introduction to Actor-Network Theory" (Oxford University Press: Oxford)

Latour B Jensen P Venturini T, 2012, "The Whole is Always Smaller Than Its Parts" British Journal of Sociology

Lemke T, 1991, “'The birth of bio-politics': Michel Foucault's lecture at the Collège de France on neo-liberal governmentality" Economy and Society 30 190-207

Luthar S S, Cicchetti D Becker B, 2000, "The Construct of Resilience: A Critical Evaluation and Guidelines for Future Work" Child Development 71 543-562

Macleod G Goodwin M, 1999, "Reconstructing an urban and regional political economy: on the state, politics, scale and explanation" Political Geography 16 123-144

Manson S, 2008, “Does scale exist? An epistemological scale continuum for complex humanenvironment systems" Geoforum 39 776-788

Manyena S B, 2006, "The concept of resilience revisited" Disasters 30 433-450 
Masten A S, 2001, "Ordinary magic: Resilience processes in development" American Psychologist 56 227-238

Masten A S Powell J L, 2003, "A Resilience framework for research, policy, and practice" in Resilience and Vulnerability Ed S S Luthar (Cambridge University Press: Cambridge) pp 1-25

Mitchell K, 2001, "Transnationalism, neoliberalism, and the rise of the shadow state" Economy and Society 30 165-189

MacKinnon D, 2011, "Reconstructing scale: towards a new scalar politics" Progress in Human Geography 35 21-36

Marston S, 2000, "The social construction of scale" Progress in Human Geography 24 219242

Martson S, Jones III J P and Woodward K, 2005, "Human geography without scale" Transactions of the Institute of British Geographers 30 416-432 
Moore A, 2008, "Rethinking scale as a geographical category: from analysis to practice" Progress in Human Geography 32 203-225

Mythen G Walklate S, 2006, "Criminology and Terrorism" British Journal of Criminology 46 379-398

NSS, 2010, "A Strong Britain in an Age of Uncertainty: The National Security Strategy", Ministry of Defence, London, http://www.mod.uk/Defencelnternet/DefenceNews/DefencePolicyAndBusiness/NationalSe curityStrategyPublished.htm

Nye M Whitmarsh L Foxton T, 2010, "Sociopsychological perspectives on the active roles of domesticactors in transition to a lower carbon electricity economy" Environment and Planning A 42 697-714

Paasi A, 1996, Territory, Boundaries and Consciousness: The Changing Geographies of the Finish-Russian Border (Wiley and Sons: Chichester)

Pain R, and Smith S J, (2008) Fear: critical geopolitics and everyday life (Ashgate: Aldershot) 
Peck J, 2011, “Neoliberal Suburbanism: Frontier Space” Urban Geography 32 884-919

Perreault T, 2005, "State restructuring and the scale politics of rural water governance in Bolivia" Environment and Planning A 37 263-284

Pitt M, 2007, "Lessons from the 2007 floods: executive summary", Cabinet Office, London, http://webarchive.nationalarchives.gov.uk/20100807034701/http:/archive.cabinetoffice.go v.uk/pittreview/thepittreview/final_report.html

PR Web, 2010, "Spike in teleconferencing blamed on Icelandic volcano disruption" PR Web, http://www.prweb.com/releases/2010/04/prweb3906694.htm

Price G N, 2008, "Hurricane Katrina: Was there a political economy of death?" Review of Black Political Economy 35 163-180

Raco M Street E, 2012, “Resilience Planning, Economic Change and The Politics of Postrecession Development in London and Hong Kong" Urban Studies 49 1065-1087

Rose N, 1996, "The death of the social? Re-figuring the territory of government" Economy and Society 25 327-356 
Rose A, 2007, “Economic Resilience to Natural and Man-made Disasters: Multidisciplinary Origins and Contextual Dimensions" Environmental Hazards 7 383-95.

SFPS consultation, 2010, "Summary of consultation responses" , Cabinet Office, London, https://update.cabinetoffice.gov.uk/resource-library/strategic-framework-and-policystatement-improving-resilience-critical-infrastructu

Smith N, 1992, "Contours of a spatialized politics: homeless vehicles and the production of geographic space" Social Text 33 54-81

Smith, 1993, "Homeless/global: scaling places" in Eds J Bird B Curtis T Putnam G Robertson L Tickner Mapping the Futures: local cultures, global change (Routledge: London) pp 87-119 Swyngedouw E, 2007, “Technonatural revolutions: the scalar politics of Franco's hydrosocial dream for Spain, 1939-1975"Transactions of the Institute of British Geographers 32 928

Walker J Cooper M, 2011, "Genealogies of resilience: From systems ecology to the political economy of crises and adaptation" Security Dialogue 42 143-160 
Wolfe P, 2008, "The implications of an increasingly decentralised energy system" Energy policy 36 4509-4513 